\title{
Effects of Saccharomyces cerevisiae fermentation products on dairy calves: Ruminal fermentation, gastrointestinal morphology, and microbial community
}

\author{
J. X. Xiao, ${ }^{* 1}$ G. M. Alugongo, ${ }^{* 1}$ R. Chung,† S. Z. Dong, ${ }^{*}$ S. L. Li, ${ }^{*}$ I. Yoon,† Z. H. Wu, ${ }^{*}$ and Z. J. Cao*2 \\ *State Key Laboratory of Animal Nutrition, College of Animal Science and Technology, China Agricultural University, Beijing 100193, P. R. China \\ †Diamond V, Cedar Rapids, IA 52404
}

\begin{abstract}
The aim of this study was to evaluate the effects of Saccharomyces cerevisiae fermentation products (SCFP) in the calf starter and milk on ruminal fermentation, gastrointestinal morphology, and microbial community in the first $56 \mathrm{~d}$ of life. Thirty Holstein bull calves were randomly assigned to 1 of 3 groups: a texturized calf starter containing $0(\mathrm{CON}), 0.5$, or $1 \%$ SCFP (XPC, Diamond V, Cedar Rapids, IA) of dry matter from d 4 to 56. In addition, the XPC-supplemented calves were fed with $1 \mathrm{~g} / \mathrm{d}$ SCFP (SmartCare, Diamond V, Cedar Rapids, IA) in milk from d 2 to 30. All calves were fed $4 \mathrm{~L}$ of colostrum within $1 \mathrm{~h}$ of birth and were subsequently fed milk twice daily until weaned on d 56. Rumen fluid was collected by an esophageal tube $4 \mathrm{~h}$ after the morning feeding on $\mathrm{d}$ 28 and 56 to determine ruminal $\mathrm{pH}$, ammonia- $\mathrm{N}$, and volatile fatty acids concentrations. On d 56,15 ( 5 per treatment) calves were harvested and slaughter weight, gastrointestinal morphology parameters, and bacteria community were recorded. Papilla length, width, and surface area were measured from 5 locations within the rumen. Villus height, width, surface area, crypt depth, and villus height-to-crypt depth ratio were measured in the duodenum, jejunum, and ileum. Next-generation sequencing technology was used to test the microbial community of the rumen and duodenum samples on $\mathrm{d}$ 28 and 56. Data were analyzed by MIXED procedure in SAS (SAS Institute Inc., Cary, NC) with contrast statements to declare CON versus all SCFP and 0.5 versus $1 \% \mathrm{SCFP}$ in starter grains. Ruminal $\mathrm{pH}$, ammonia-N, and total volatile fatty acids were not altered by SCFP. However, the supplemented groups exhibited higher ruminal butyrate concentrations coinciding with higher Butyrivibrio and lower Prevotella richness than CON group. Supplementation of SCFP increased papilla length in the rumen. In the small intestine, SCFP
\end{abstract}

Received October 26, 2015.

Accepted February 27, 2016.

${ }^{1}$ These authors contributed equally to this work.

${ }^{2}$ Corresponding author: caozhijun@cau.edu.cn reduced crypt depth of jejunum, and increased villus height-to-crypt depth ratio in all segments of the small intestine, especially when supplemented at a higher dosage in the starter. In conclusion, Saccharomyces cerevisiae fermentation products improved gastrointestinal morphology, possibly due to increased Butyrivibrio and decreased Prevotella richness of the rumen fluid, which resulted in an increase in butyrate production, and the effect was slightly greater with the higher dosage of SCFP in the starter.

Key words: calf, Saccharomyces cerevisiae fermentation products, gastrointestinal morphology, microbial community

\section{INTRODUCTION}

Saccharomyces cerevisiae fermentation products (SCFP) are commonly used as feed additives, which contain compounds including oligosaccharides, organic acids, AA, and peptides, which can benefit the various types of bacteria (Callaway and Martin, 1997), protozoa (Arakaki et al., 2000), and fungi (Mao et al., 2013) in the gastrointestinal tract. In mature ruminants, SCFP has been shown to influence milk production (Poppy et al., 2012), VFA concentrations, ruminal pH (Yoon and Stern, 1996), and DMI (Dann et al., 2000). In preruminant calves, supplementation of SCFP has been shown to improve survival of calves, which resulted in greater profit margin (Magalhães et al., 2008), better ADG, body structure (Lesmeister et al., 2004a), and slightly promoted VFA production (Quigley et al., 1992) and ruminal morphology development (Brewer et al., 2014). However, the effect of supplementing SCFP in diets of calves on gastrointestinal epithelium development and microbial community has not been fully evaluated.

The rumen is typically the main digestive and absorptive organ for VFA and excess ammonia-N in ruminants, whereas protein occurs further down the tract. As important parameters of gastrointestinal health and growth, rumen microbes, ruminal $\mathrm{pH}$, ammonia-N, and VFA are of interest. Volatile fatty acids, as the main energy substrate produced in the rumen by microbial fermentation (Bergman, 1990), are rapidly absorbed 
across the rumen epithelium and can contribute up to $80 \%$ of the energy requirements of ruminants (Gäbel and Sehested, 1997). The development of rumen morphology is closely associated with VFA production and absorption and is especially affected by butyrate and propionate concentrations (Saner et al., 1959; Weigand et al., 1975; Sakata and Tamate, 1978). Saccharomyces cerevisiae fermentation products have the ability to accelerate the production of VFA (Quigley et al., 1992); thus, improvement in rumen morphology may be found when SCFP is supplemented in the starter. As for the intestines, previous studies have illustrated that piglets (Shen et al., 2009) and broilers (Gao et al., 2008) fed SCFP had a greater improvement in morphology; however, this kind of study is lacking in calves. Therefore, we hypothesized that the inclusion of SCFP both in milk and starter in calf feeding might accelerate the rumen and intestinal epithelium development, with the higher inclusion in the starter exerting a greater response. Conversely, gastrointestinal microbiota plays an important role in digestive tract, which is also unstable in preweaning calves (Li et al., 2012). Another objective of our work was to investigate the effect of SCFP on the microbial colonization of the rumen and intestine of preweaning calves.

\section{MATERIALS AND METHODS}

\section{Treatments, Animals, and Feeding}

This study was conducted at the Dairy Teaching and Research Farm (Shunyi, Beijing, China), which has approximately 2,000 milking cows. The experiment was conducted as a randomized complete block design with 30 male calves. Initial BW was measured on d 2 and calves selected ranged from 35 to $45 \mathrm{~kg}$ to reduce the difference among individuals. Only calves with successful passive transfer of immunity, determined by clinical refractometer $24 \mathrm{~h}$ after birth, were used $[\geq 5.5 \mathrm{~g} / \mathrm{dL}$ of serum total protein (TP); Trotz-Williams et al., 2008]. Calves were enrolled in the experiment over a period of 1 mo, from May to June 2014, and 3 calves were grouped as a block by an order of birth date, within each block. Selected calves (initial $\mathrm{BW}=40 \pm 5 \mathrm{~kg}$; $\mathrm{TP} \geq 5.5 \mathrm{~g} /$ $\mathrm{dL})$ were randomly assigned to 1 of 3 treatments: control [CON; no SmartCare or XPC (Diamond V, Cedar Rapids, IA)], $1 \mathrm{~g} / \mathrm{d}$ SmartCare in the milk $+0.5 \%$ XPC in the starter (SCFP1), and $1 \mathrm{~g} / \mathrm{d}$ SmartCare in the milk $+1 \%$ XPC in the starter (SCFP2). Calves were subsequently housed in individual hutches and placed on straw that was replaced weekly. The XPC (Original XPC, Diamond V) was incorporated in the starter at rates of $0,0.5$, and $1 \%$ on an as-fed basis from d 4 to 56 , mixed with other ingredients, and pelleted. SmartCare
(Diamond V) was added into milk daily at 0 or $1 \mathrm{~g} /$ head per day in the morning milk feeding from $\mathrm{d} 2$ to 30.

All calves received $4 \mathrm{~L}$ of colostrum immediately after birth and thereafter were fed pasteurized nonsaleable milk twice per day at 0800 and $1500 \mathrm{~h}[3 \mathrm{~L} /$ feeding $(6 \mathrm{~L} / \mathrm{d})$ from d 2 to $10,4 \mathrm{~L} /$ feeding $(8 \mathrm{~L} / \mathrm{d})$ from $\mathrm{d}$ 11 to $42,3 \mathrm{~L} /$ feeding $(6 \mathrm{~L} / \mathrm{d})$ from d 43 to 49 , and 2 L/feeding $(4 \mathrm{~L} / \mathrm{d})$ from d 50 to 56]. Nonsaleable milk was pasteurized using a milk pasteurizer where milk temperature was elevated and held at $60^{\circ} \mathrm{C}$ for $30 \mathrm{~min}$ and then cooled to $37^{\circ} \mathrm{C}$.

Calf starter ingredients and nutrient composition are presented in Table 1. Ingredient composition was identical between treatments with the exception of SCFP content, which replaced corn germ meal. Nutrient composition of starter met or exceeded the requirements for pre-weaned Holstein calves as suggested by NRC (2001). Starter grain (Honneur Nutritional Technology Co. Ltd., Beijing, China) was offered once every day in the morning, immediately after milk feeding, for ad libitum intake during the first $56 \mathrm{~d}$ of age. Water was provided ad libitum after $1 \mathrm{~h}$ of milk feeding.

\section{Sample Collection}

Blood Collection and Analysis. Blood was sampled from all calves before the morning feeding on $\mathrm{d}$ 28 and 56 for BHB analysis as an indicator of energy status of calves. Using evacuated tubes containing no anticoagulant, blood was collected via the jugular vein and then centrifuged at $3,500 \times g$ for $15 \mathrm{~min}$ at $4^{\circ} \mathrm{C}$. Serum was collected in $1.5-\mathrm{mL}$ microtubes and stored at $-20^{\circ} \mathrm{C}$ for later analysis. Blood BHB concentrations were determined based on the enzymatic oxidation of BHB to acetoacetate and concomitant reduction of $\mathrm{NAD}^{+}$to NADH (Williamson et al., 1962) by using an automated biochemistry Analyzer (model GF-D200, Caihong Co., Shandong, China) and a spectrophotometer (model 722, Caihong Co.).

Harvest. On d 56 of age, 15 calves (5 per treatment) were harvested and samples of gastrointestinal tissues and contents were collected. After harvest, the abdominal cavity was immediately opened and each region of digestive tract (rumen, duodenum, jejunum, and ileum) was isolated and tied off. Samples were collected as described below.

Rumen Fluid and Content. Rumen contents from the harvested, tied-off rumens were collected and separated into the solid and liquid portions by squeezing through 4 layers of cheesecloth. Solid contents were placed into sterile tubes, quick-frozen in liquid nitrogen, and then stored at $-80^{\circ} \mathrm{C}$ for later analysis of microbial composition and populations (Prates et al., 2010; 
Fliegerova et al., 2014). Rumen fluid was also collected on d 28 and 56 of age by a flexible esophageal tube $(2$ $\mathrm{mm}$ of wall thickness and $6 \mathrm{~mm}$ of internal diameter; Anscitech Co. Ltd., Wuhan, Hubei, China) from all calves $4 \mathrm{~h}$ after the morning milk feeding (Morales et al., 2014). Rumen $\mathrm{pH}$ was measured immediately with a glass electrode $\mathrm{pH}$ meter. Five milliliters of rumen fluid was stored at $-80^{\circ} \mathrm{C}$ for microbial analysis and another $5 \mathrm{~mL}$ was preserved at $-20^{\circ} \mathrm{C}$ for later analysis of VFA (Erwin et al., 1961) and ammonia-N concentrations (Broderick and Kang, 1980).

Intestinal Contents. Intestinal contents from duodenums were collected into sterile tubes and stored at $-80^{\circ} \mathrm{C}$ for later microbial analysis. All samples were separately stored and no samples were pooled (Vlková et al., 2006; Suchodolski et al., 2008).

Rumen and Intestinal Tissues. After removing the digesta, tissues from the rumen, duodenum, jejunum, and ileum were rinsed in saline. Two $1-\mathrm{cm}^{2}$ rumen tissue samples were removed from the center of each area of cranial ventral sac (RA), ventral portion of caudal ventral sac (RB), caudal portion of caudal ventral sac (RC), cranial dorsal sac (RD), and caudal dorsal sac (RE). The tissue samples were then fixed in $4 \%$ phosphate-buffered paraformaldehyde solution (4\% PBPS) for later analysis. From each rumen tissue sample, 5 papillae $(\mathrm{n}=10$ in each area) were randomly selected for papillae length $(\mathbf{P L})$ and papillae width (PW) measurement (Lesmeister et al., 2004b). The cross-sectional papillae surface area (PSA) was determined by multiplying PL by PW. For small intestines, a 4-cm-long looped section from mid-duodenum, mid-jejunum, and mid-ileum was placed into $4 \%$ PBPS (Bühler et al., 1998; Roffler et al., 2003) and sent for morphological analysis (Beijing Raise Dragon Co. Ltd., Beijing, China). The samples were separately cut into two 1-mm-thick cross-sections, washed, and then embedded in paraffin blocks. For each block, 5 cuts of 3 - to $4-\mu \mathrm{m}$ thick sections were isolated, resulting in 10 regions of each intestinal site for morphological quantitative and qualitative analysis (Zitnan et al., 2003). Section pictures (Olympus CX 31, Olympus Corp., Tokyo, Japan) were taken and quantitative morphometric analyses (Mirs Image Pro. Zip, Beijing Research Technology Develop Co. Ltd., Beijing, China) were conducted to measure villus height $(\mathbf{V H})$, villus width (VW), and crypt depth (CD). Cross-sectional villus surface area (VSA) was calculated by multiplying VH by VW, whereas villus height-to-crypt depth ratio (VCR) was determined by dividing VH by CD. Finally, the rinsed rumen, reticulum, omasum, and abomasum were weighed and values were recorded after sampling.

Bacteria (Genus) Richness. Next-generation sequencing technology was used to test the microbial community in samples of rumen liquid collected on $\mathrm{d}$ 28 (RL28) and 56 (RL56), rumen solid content col-

Table 1. Ingredient and nutrient composition of the starter without (CON) or with Saccharomyces cerevisiae fermentation products (XPC)

\begin{tabular}{lccc}
\hline Item & CON & $0.5 \%$ XPC & $1 \%$ XPC \\
\hline Ingredient (\%) & & & \\
Steam-flaked corn & 33.1 & 33.1 & 33.1 \\
Wheat bran & 7.6 & 7.6 & 7.6 \\
Soybean meal & 14.3 & 14.3 & 14.3 \\
Extruded soybean & 4.2 & 4.2 & 4.2 \\
Canola meal & 8.0 & 8.0 & 8.0 \\
Corn germ meal & 8.5 & 8.0 & 7.5 \\
Rice powder & 4.2 & 4.2 & 4.2 \\
Milk powder & 0.4 & 0.4 & 0.4 \\
DDGS & 16.0 & 16.0 & 16.0 \\
CaCO & 1.4 & 1.4 & 1.4 \\
CaHPO & 1.0 & 1.0 & 1.0 \\
NaCl & 0.7 & 0.7 & 0.7 \\
Mycotoxin binder & 0.1 & 0.1 & 0.1 \\
Premix compound for calf ${ }^{1}$ & 0.5 & 0.5 & 0.5 \\
XPC & 0 & 0.5 & 1.0 \\
Nutrient composition, DM basis (\%, unless noted) & & & \\
DM & 90.9 & 91.8 & 90.5 \\
$\mathrm{CP}_{\mathrm{NE}}$ (Mcal/kg) & 19.6 & 18.9 & 18.7 \\
$\mathrm{NDF}$ & 1.73 & 1.73 & 1.73 \\
$\mathrm{ADF}$ & 21.3 & 20.3 & 20.7 \\
Ca & 8.2 & 7.9 & 8.1 \\
$\mathrm{P}$ & 0.97 & 0.97 & 0.97 \\
\hline
\end{tabular}

${ }^{1}$ Premix compound contained $(\mathrm{mg} / \mathrm{kg})$ copper 60 , iron 60 , zinc 80 , manganese 80 , cobalt 0.4 , iodine 1 , and selenium 1. The premix also contained (IU/g) vitamin A 12,000, vitamin D 3,000, and vitamin E 120.

${ }^{2}$ Diamond V (Cedar Rapids, IA). 
lected on d 56 (RS56), and duodenal content collected on d 56 (DC56). A total of 60 samples (5 calves $\times 3$ treatments $\times 4$ samples) were collected (not pooled) for DNA extraction, amplification, and sequencing. Based on the $\mathrm{V} 3$ region of $16 \mathrm{~S}$ rDNA, trimmed DNA samples were sequenced using the pair-end method (Bartram et al., 2011) by Illumina HiSeq platform (Beijing Computing Center, Beijing, China). After sequencing, the highquality sequences were clustered (UCLUST v1.2.22, http://www.drive5.com/usearch/index.html; Edgar, 2010) into operational taxonomic units (OTU), defined as comprising sequences with less than a $3 \%$ difference as detected in DOTUR (Schloss and Handelsman, 2005) by the furthest-neighbor method. For OTU comparison among each sample, we standardized the OTU for later diversity and abundance analyses through equating the sequence number to 70,000 reads. Total sequences from OTU were used to compare the databases (Greengene and RDP, http://greengenes.secondgenome.com/downloads/database/13_5; Malmuthuge and Griebel, 2014) to assign in different taxa (QIIME). Microbial composition graphs were then generated at a genus level.

\section{Statistical Analyses}

Data were analyzed as a randomized complete block design. Continuous variables with repeated measurements including ruminal VFA, ammonia- $\mathrm{N}$ and $\mathrm{pH}$, blood BHB, and ruminal and intestinal bacteria richness within the same calf were analyzed using MIXED procedure of SAS (SAS Institute Inc., Cary, NC) with the fixed effects of treatment, day of measurement, interaction between treatment and day of measurement, and the random effect of calf nested within treatment. Variables of gastrointestinal morphological parameters with repeated measures of different area were also analyzed using MIXED with the fixed effects of treatment, area of measurement (rumen: RA, RB, RC, RD, RE; small intestines: duodenum, jejunum, ileum), and the random effect of calf nested within treatment. Variables with a single measurement during the study, such as harvested weight, were analyzed with the fixed effects of treatment of calf and the random effect of calf nested within treatment. Orthogonal contrasts were completed using contrast statements to declare CON versus SCFP (SCFP1 and SCFP2) and SCFP1 (0.5\% SCFP in starter) versus SCFP2 (1\% SCFP in starter). All treatment results are reported as least squares means. Significant differences were indicated at $P \leq 0.05$, with trends were declared at $0.05<P \leq 0.10$.

\section{RESULTS}

\section{Rumen Fermentation, Blood BHB, and Slaughter Weight}

Least squares means for ruminal $\mathrm{pH}$, ammonia-N, and blood BHB are in Table 2. Throughout the study, ruminal $\mathrm{pH}$ was similar $(P>0.05)$ between treatments and averaged 5.71 and 5.29 on d 28 and 56 , respectively. Likewise, ammonia-N was not different between CON and treatment groups on d $28(P=0.28)$ or 56 $(P=0.31)$. There tended to be a treatment by day interaction $(P<0.10)$ for concentration of ammonia-N. It was interesting to find that ammonia- $\mathrm{N}$ increased by $2.2 \mathrm{mg} / \mathrm{dL}$ from d 28 to 56 in the CON calves and decreased by 1.27 and $0.76 \mathrm{mg} / \mathrm{dL}$ when calves were supplemented with 0.5 and $1 \%$ SCFP in starter, respectively. We observed no effects of treatment on BHB concentrations.

No differences between treatment and CON group for VFA concentrations were found, except for butyrate concentrations (Table 3 ). Calves supplemented with SCFP exhibited higher $(P<0.05)$ ruminal butyrate concentrations than CON calves (9.38 vs. 4.07 and 13.27 vs. $8.46 \mathrm{mmol} / \mathrm{L}$ for $\mathrm{d} 28$ and 56, respectively). Some numerical differences were noted in acetate, propionate, isovalerate, valerate, and total VFA concentrations among treatments, but these parameters did not significantly differ. As expected, we found a significant time effect $(P<0.001)$ on VFA concentrations and ru-

Table 2. The effect of Saccharomyces cerevisiae fermentation products $(\mathrm{SCFP})^{1}$ on ruminal $\mathrm{pH}$, ammonia-N, and blood BHB in dairy calves

\begin{tabular}{|c|c|c|c|c|c|c|c|c|}
\hline Item & $\mathrm{N}^{2}$ & Day & \multicolumn{3}{|c|}{ Mean } & SEM & \multicolumn{2}{|c|}{$P$-value } \\
\hline $\mathrm{pH}$ & 30 & 56 & 5.23 & 5.32 & 5.33 & 0.26 & 0.70 & 0.97 \\
\hline \multirow{2}{*}{ Ammonia N (mg/dL) } & 30 & 28 & 10.06 & 12.03 & 11.25 & 1.20 & 0.28 & 0.61 \\
\hline & 30 & 56 & 12.26 & 10.81 & 10.48 & 1.29 & 0.31 & 0.85 \\
\hline $\mathrm{BHB}^{2}(\mathrm{mmol} / \mathrm{L})$ & 30 & 28 & 0.34 & 0.31 & 0.36 & 0.04 & 0.90 & 0.15 \\
\hline
\end{tabular}

$\overline{{ }^{1} \mathrm{CON}}=$ no SmartCare or XPC; SCFP1 $=1 \mathrm{~g} /$ head/per day SmartCare in milk $+0.5 \%$ XPC in the starter grains; SCFP2 $=1 \mathrm{~g} /$ head per day SmartCare in milk $+1 \%$ XPC in the starter grains (Diamond V, Cedar Rapids, IA).

${ }^{2} \mathrm{~N}=$ number of calves used $(\mathrm{CON}=10, \operatorname{SCFP} 1=10$, SCFP $2=10)$. 
Table 3. The effect of Saccharomyces cerevisiae fermentation products $(\mathrm{SCFP})^{1}$ on ruminal VFA ${ }^{2}$ in dairy calves

\begin{tabular}{|c|c|c|c|c|c|c|c|c|}
\hline Item & $\mathrm{N}^{3}$ & Day & \multicolumn{3}{|c|}{ Mean } & SEM & \multicolumn{2}{|c|}{$P$-value } \\
\hline Acetate $(\mathrm{mmol} / \mathrm{L})$ & 30 & 28 & 24.71 & 25.38 & 26.50 & 2.54 & 0.69 & 0.74 \\
\hline Propionate $(\mathrm{mmol} / \mathrm{L})$ & 30 & 28 & 19.41 & 20.59 & 22.34 & 2.23 & 0.45 & 0.55 \\
\hline & 30 & 56 & 67.16 & 75.23 & 71.37 & 5.75 & 0.38 & 0.62 \\
\hline Acetate-to-propionate ratio & 30 & 28 & 1.27 & 1.27 & 1.21 & 0.07 & 0.78 & 0.51 \\
\hline & 30 & 56 & 8.46 & 12.28 & 14.27 & 2.21 & 0.08 & 0.51 \\
\hline \multirow{2}{*}{ Isovalerate $(\mathrm{mmol} / \mathrm{L})$} & 30 & 28 & 0.33 & 0.61 & 0.42 & 0.14 & 0.27 & 0.29 \\
\hline & 30 & 56 & 1.63 & 2.05 & 2.24 & 0.48 & 0.38 & 0.76 \\
\hline \multirow[t]{2}{*}{ Valerate $(\mathrm{mmol} / \mathrm{L})$} & 30 & 28 & 0.59 & 0.64 & 0.83 & 0.17 & 0.49 & 0.42 \\
\hline & 30 & 56 & 4.31 & 4.76 & 4.00 & 0.55 & 0.92 & 0.32 \\
\hline \multirow[t]{2}{*}{ Total $(\mathrm{mmol} / \mathrm{L})$} & 30 & 28 & 50.29 & 56.04 & 62.25 & 5.33 & 0.17 & 0.38 \\
\hline & 30 & 56 & 152.40 & 170.20 & 166.56 & 12.62 & 0.30 & 0.83 \\
\hline
\end{tabular}

${ }^{1} \mathrm{CON}=$ no SmartCare and XPC; SCFP1 $=1 \mathrm{~g} /$ head per day SmartCare in milk $+0.5 \%$ XPC in the starter grains; SCFP2 $=1 \mathrm{~g} /$ head per day SmartCare in milk $+1 \%$ XPC in the starter grains (Diamond V, Cedar Rapids, IA).

${ }^{2}$ Total and individual VFA values were from ruminal fluid obtained via esophageal tubing.

${ }^{3} \mathrm{~N}=$ number of calves used $(\mathrm{CON}=10, \operatorname{SCFP} 1=10$, SCFP $2=10)$.

minal $\mathrm{pH}$ as the calves grew older and DMI increased. Rumen (average $948.5 \mathrm{~g})$, reticulum $(157.1 \mathrm{~g})$, omasum (220.5 g), abomasum (427.9 g), and harvest BW (69.2 $\mathrm{kg}$ ) recorded on d 56 showed no significant treatment effect (Table 4).

\section{Rumen Morphology}

Effects of SCFP on PL and PW in the rumen are presented in Table 5. Calves fed SCFP exhibited greater $\mathrm{PL}$ of RA $(P=0.04), \mathrm{RB}(P=0.01), \mathrm{RE}(P=0.03)$, and ER $(P=0.002)$, showed significantly higher PW of ER $(P=0.002)$, and tended to have greater $\mathrm{PW}$ of $\mathrm{RB}(P=0.08)$ and $\mathrm{RC}(P=0.06)$ than $\mathrm{CON}$ calves. The PSA of RA $(P=0.03), \mathrm{RB}(P=0.02), \mathrm{RC}(P=$ $0.09)$, RD $(P=0.06)$, RE $(P=0.02)$, and ER $(P<$ $0.001)$ were found to be greater in SCFP treated calves compared with CON.
Evaluation of all rumen areas (RA, RB, RC, RD, RE, and ER) indicated no significant difference between SCFP1 and SCFP2 among PL, PW, and PSA, with the exception of PL of RD and ER. Calves supplemented with SCFP2 tended to have greater PL of RD $(P=$ $0.07)$ and ER $(P=0.08)$ compared with SCFP1. In short, calves supplemented with SCFP increased PL, PW and PSA growth compared with those fed CON diet, with the higher dosage rate showing potentially better function in promoting PL growth, but not PW and PSA.

\section{Intestine Morphology}

Least squares means for VH, VW, VSA, CD, and VCR were measured to determine the effect of SCFP on intestine morphology (Table 6). With the exception of higher VH of ESI $(P=0.002)$ in SCFP, numerical

Table 4. The effect of Saccharomyces cerevisiae fermentation products $(\mathrm{SCFP})^{1}$ on harvested weight in dairy calves

\begin{tabular}{|c|c|c|c|c|c|c|c|}
\hline Item $^{2}$ & $\mathrm{~N}^{3}$ & \multicolumn{3}{|c|}{ Mean } & SEM & \multicolumn{2}{|c|}{$P$-value } \\
\hline Reticulum (g) & 15 & 145.2 & 163.0 & 163.2 & 11.48 & 0.23 & 0.99 \\
\hline Reti-rumen (g) & 15 & $1,073.4$ & $1,138.8$ & $1,104.8$ & 63.27 & 0.54 & 0.71 \\
\hline Omasum $(\mathrm{g})$ & 15 & 209.6 & 223.8 & 228.2 & 21.2 & 0.54 & 0.89 \\
\hline Abomasum (g) & 15 & 436.4 & 443.0 & 404.2 & 26.58 & 0.70 & 0.32 \\
\hline
\end{tabular}

${ }^{1} \mathrm{CON}=$ no SmartCare and XPC; SCFP1 $=1 \mathrm{~g} /$ head per day SmartCare in milk $+0.5 \%$ XPC in the starter grains; SCFP2 $=1 \mathrm{~g} /$ head per day SmartCare in milk $+1 \%$ XPC in the starter grains (Diamond V, Cedar Rapids, IA).

${ }^{2}$ Reti-rumen $(\mathrm{g})=$ reticulum $(\mathrm{g})+$ rumen $(\mathrm{g})$; Total $(\mathrm{g})=$ whole stomach weight; Harvest weight $(\mathrm{g})=$ BW excluding blood and gastrointestinal chyme.

${ }^{3} \mathrm{~N}=$ number of calves used $(\mathrm{CON}=5, \operatorname{SCFP} 1=5, \operatorname{SCFP} 2=5)$. 
differences $(P>0.05)$ were detected between SCFP and $\mathrm{CON}$ for $\mathrm{VH}, \mathrm{VW}$, or VSA of any segments in the duodenum, jejunum, and ileum. And calves fed SCFP showed lower CD $(P<0.05)$ of jejunum and ESI $(P=$ $0.07)$ than those fed the CON diet. Calves supplemented with SCFP also had significantly improved VCR in the jejunum $(P<0.01)$, ileum $(P=0.02)$, and ESI $(P$ $=0.002)$. No differences were noted between SCFP1 and SCFP2 in VH, VW, VSA, and CD; however, calves supplemented with the higher dosage of SCFP (SCFP2) exhibited a greater VCR in the ESI $(P=0.03)$ and a tendency for greater VCR in the duodenum $(P=0.09)$.

Although it had limited effects on VW and VSA, SCFP had an ability to increase VH and decrease the $\mathrm{CD}$, which resulted in improved VCR. A greater effect was observed when supplemented at the higher dosage of SCFP (SCFP2) in the starter compared with the lower dosage (SCFP1).

\section{Bacteria (Genus) Richness}

After sequencing all 60 collected samples, observed bacterial species of RL28, RL56, RS56, and DC56 were between 634 and 1,366, 703 and 1,056, 809 and 1,248, and 643 and 2,280 OTU, respectively. The relative richness of the top 10 bacteria genus (percent of total reads) is presented in Figure 1. These bacteria were identified mainly as Prevotella $(21.8,36.3,40.3$, and $43.5 \%$ average occurrence for RL28, RL56, RS56, and DC56, respectively), unknown genus $(40.4,36.5,30.9$, and $31.6 \%$ ), and Butyrivibrio (22.1, 15.8, 15.5, and 5.7\%). No treatment effects were observed in the RS56 and DC56 for any bacteria; however, SCFP supplementation was found to decrease relative occurrence of Prevotella at RL28 (4.2 fold compared with the CON, $P=0.01$ ) and a tendency at RL56 (1.6 fold, $P=0.08$ ). An increase of relative occurrence of Butyrivibrio of RL on d 28 was noted. On average, $30.2 \%$ of OTU were dominated by members of genus Butyrivibrio when supplemented SCFP in the diet, which was much higher $(P=0.02)$ compared with CON (5.6\%). On d 56, the percentage of Butyrivibrio for CON, SCFP1, and SCFP2 was 11.7, 18.9 , and 16.6 of total reads, respectively. Supplementation of SCFP also decreased $(P<0.05)$ the richness of Shuttleworthia of RL28 and Desulfovibrio of RL56. No significant effects were observed between SCFP1 and SCFP2 for bacteria richness in all 4 samples.

\section{DISCUSSION}

\section{Rumen Fermentation and Slaughter Weight}

Very little research exists evaluating the effects of SCFP on ruminal VFA concentrations in calves. The

Table 5. The effect of Saccharomyces cerevisiae fermentation products (SCFP) ${ }^{1}$ on rumen morphology measurement in dairy calves

\begin{tabular}{|c|c|c|c|c|c|c|c|}
\hline \multirow[b]{2}{*}{ Item $^{2}$} & \multirow[b]{2}{*}{$\mathrm{N}^{3}$} & \multicolumn{3}{|c|}{ Mean } & \multirow[b]{2}{*}{ SEM } & \multicolumn{2}{|c|}{$P$-value } \\
\hline & & $\mathrm{CON}$ & SCFP1 & SCFP2 & & CON vs. SCFP & SCFP 1 vs. 2 \\
\hline \multicolumn{8}{|c|}{$\overline{\mathrm{PL}}(\mu \mathrm{m})$} \\
\hline $\mathrm{RA}$ & 15 & $1,900.3$ & $2,006.3$ & $1,963.7$ & 30.9 & 0.04 & 0.32 \\
\hline $\mathrm{RB}$ & 15 & 755.9 & 869.0 & 911.4 & 37.7 & 0.01 & 0.44 \\
\hline $\mathrm{RC}$ & 15 & 872.7 & 898.4 & 969.9 & 35.7 & 0.18 & 0.18 \\
\hline $\mathrm{RD}$ & 15 & 713.4 & 739.3 & 838.2 & 35.8 & 0.11 & 0.07 \\
\hline $\mathrm{RE}$ & 15 & 756.7 & 816.4 & 886.7 & 32.4 & 0.03 & 0.15 \\
\hline ER & 15 & $1,002.3$ & $1,065.2$ & $1,114.7$ & 26.45 & 0.002 & 0.08 \\
\hline \multicolumn{8}{|c|}{$\mathrm{PW}(\mu \mathrm{m})$} \\
\hline $\mathrm{RA}$ & 15 & 218.3 & 239.8 & 226.6 & 7.2 & 0.11 & 0.21 \\
\hline $\mathrm{RB}$ & 15 & 168.1 & 180.9 & 187.6 & 7.1 & 0.08 & 0.52 \\
\hline $\mathrm{RC}$ & 15 & 181.2 & 201.6 & 187.4 & 5.1 & 0.06 & 0.07 \\
\hline $\mathrm{RD}$ & 15 & 193.8 & 233.9 & 224.2 & 19.7 & 0.17 & 0.73 \\
\hline $\mathrm{RE}$ & 15 & 193.0 & 220.6 & 211.1 & 12.2 & 0.15 & 0.59 \\
\hline ER & 15 & 190.7 & 216.1 & 207.6 & 6.8 & 0.002 & 0.23 \\
\hline \multicolumn{8}{|c|}{ PSA $\left(\mu \mathrm{m}^{2}\right)$} \\
\hline $\mathrm{RA}$ & 15 & 418,121 & 483,114 & 447,813 & 15,687 & 0.11 & 0.21 \\
\hline $\mathrm{RB}$ & 15 & 129,227 & 158,549 & 171,679 & 11,451 & 0.08 & 0.52 \\
\hline $\mathrm{RC}$ & 15 & 159,175 & 182,453 & 182,979 & 10,602 & 0.06 & 0.07 \\
\hline $\mathrm{RD}$ & 15 & 137,759 & 170,476 & 190,037 & 16,421 & 0.17 & 0.73 \\
\hline $\mathrm{RE}$ & 15 & 147,019 & 179,114 & 187,860 & 10,973 & 0.15 & 0.59 \\
\hline $\mathrm{ER}$ & 15 & 198,619 & 235,013 & 236,697 & 8,075 & $<0.0001$ & 0.83 \\
\hline
\end{tabular}

${ }^{1} \mathrm{CON}=$ no SmartCare and XPC; SCFP1 = $1 \mathrm{~g} /$ head per day SmartCare in milk $+0.5 \%$ XPC in the starter grains; SCFP2 $=1 \mathrm{~g} /$ head per day SmartCare in milk + 1\% XPC in the starter grains (Diamond V, Cedar Rapids, IA).

${ }^{2} \mathrm{PL}=$ papillae length; $\mathrm{PW}=$ papillae width; $\mathrm{PSA}=$ papillae surface area; $\mathrm{RA}=$ cranial ventral sac; $\mathrm{RB}=$ ventral portion of the caudal ventral $\mathrm{sac} ; \mathrm{RC}=$ caudal portion of the caudal ventral sac; $\mathrm{RD}=$ cranial dorsal sac; $\mathrm{RE}=$ caudal dorsal sac; $\mathrm{ER}=\mathrm{entire}$ rumen $(\mathrm{RA}+\mathrm{RB}+\mathrm{RC}+$ $\mathrm{RD}+\mathrm{RE})$.

${ }^{3} \mathrm{~N}=$ number of calves used $(\mathrm{CON}=5, \operatorname{SCFP} 1=5, \operatorname{SCFP} 2=5)$. 
SCFP tested in this experiment increased ruminal butyrate (statistically) and other individual VFA (numerically) compared with CON on d 28 and 56. The changes in bacterial richness, particularly the increase in Butyrivibrio with SCFP supplementation, could contribute to an increased butyrate concentration. Butyrate and, to a lesser extent, propionate are used as energy sources by the rumen epithelium and subsequently have great influence on rumen epithelial development (Tamate et al., 1962). Therefore, the increased concentration of butyrate and numerically higher concentration of propionate might result in the greater ruminal papillae length observed in calves supplemented with SCFP.

Previous studies concluded that VFA production increased and $\mathrm{pH}$ decreased in preweaning calves over time (McCarthy and Kesler, 1956; Anderson et al., 1987; Quigley et al., 1991), which is similar to what was shown in this experiment. These changes could be attributed to the increase in calf starter intake, which was exhibited in another study (G. Alugongo, J. Xiao, Y. Chung, S. Z. Dong, S. Li, I. Yoon, Z. Wu, and Z. Cao, unpublished data). No treatment or day effect was observed for ammonia-N; however, a tendency was found for an interaction between treatment and day $(P$ $<0.10)$ for ammonia-N. This indicates that with an increase in age and feed intake, SCFP may improve the utilization of ruminal ammonia- $\mathrm{N}$, which may be related to SCFP increasing fiber-degrading bacteria that have a high preference for ammonia as their $\mathrm{N}$ source (Hristov et al., 2010). Other researchers, in agreement with our study, suggested a decrease in ruminal ammonia-N when calves were fed SCFP supplemented diets (Kumar et al., 1994).

Supplementation with SCFP has been shown to improve BW and ADG of animals (Lesmeister et al., 2004a; Gao et al., 2008); however, we did not find statistical differences between SCFP and CON in slaughter weight. Only numerical improvements were observed in rumen, reticulum, omasum, and harvest weights when SCFP was added in the diet in the present study.

\section{Blood BHB}

Calves rely upon glucose as the primary energy substrate due to the limited utilization of VFA in undeveloped epithelium (Heinrichs and Lesmeister, 2005). However, as starter intake increases and rumen

Table 6. The effect of Saccharomyces cerevisiae fermentation products (SCFP) ${ }^{1}$ on small intestinal morphology measurement in dairy calves

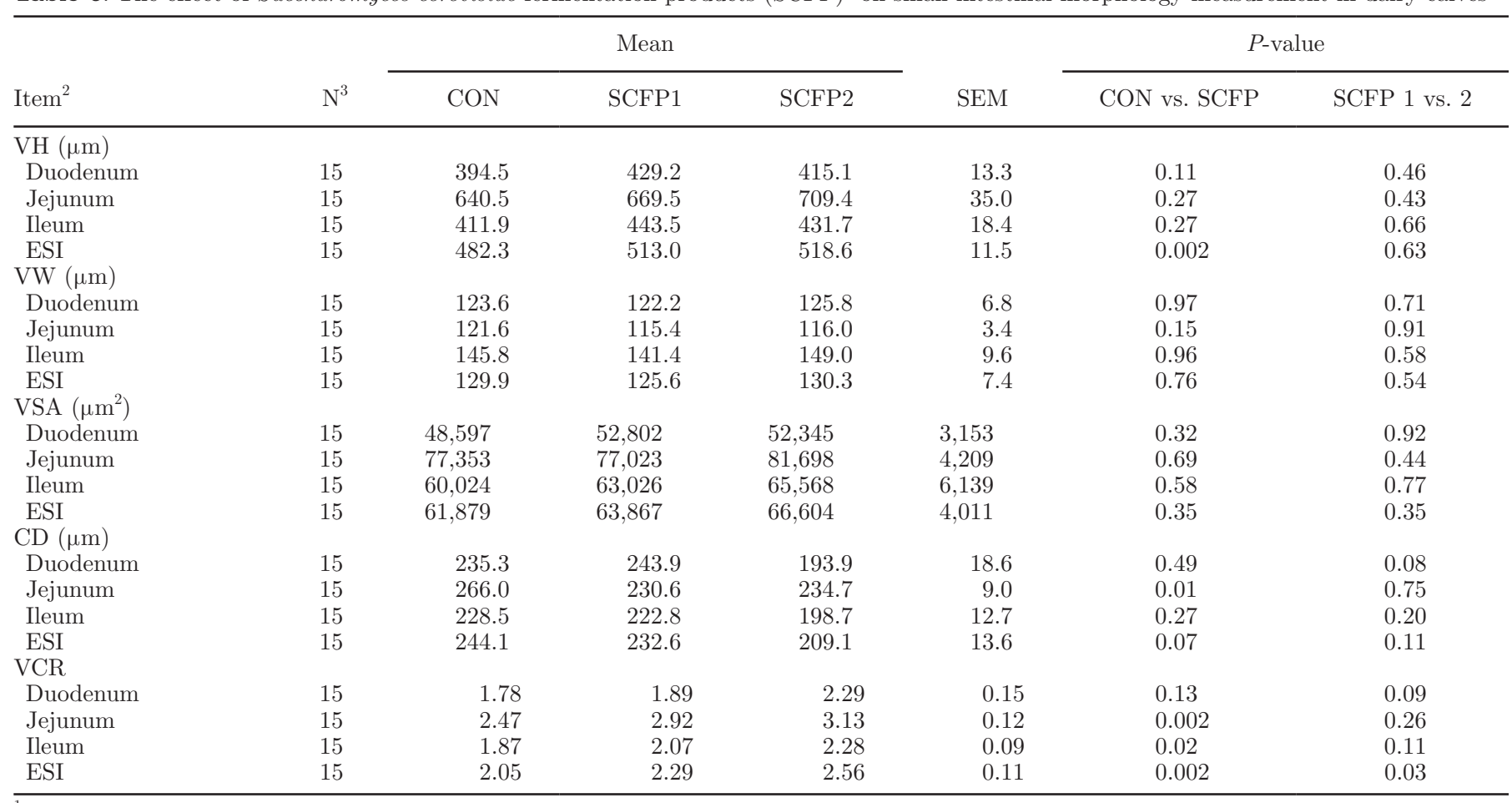

${ }^{1} \mathrm{CON}=$ no SmartCare and XPC; SCFP1 $=1 \mathrm{~g} /$ head per day SmartCare in milk $+0.5 \%$ XPC in the starter grains; SCFP2 $=1 \mathrm{~g} /$ head per day SmartCare in milk + 1\% XPC in the starter grains (Diamond V, Cedar Rapids, IA).

${ }^{2} \mathrm{VH}=$ villus height; VW $=$ villus width; VSA = villus surface area; CD = crypt depth; VCR = villus-to-crypt ratio; ESI $=$ entire small intestines (duodenum + jejunum + ileum).

${ }^{3} \mathrm{~N}=$ number of calves used $(\mathrm{CON}=5, \operatorname{SCFP} 1=5, \operatorname{SCFP} 2=5)$. 

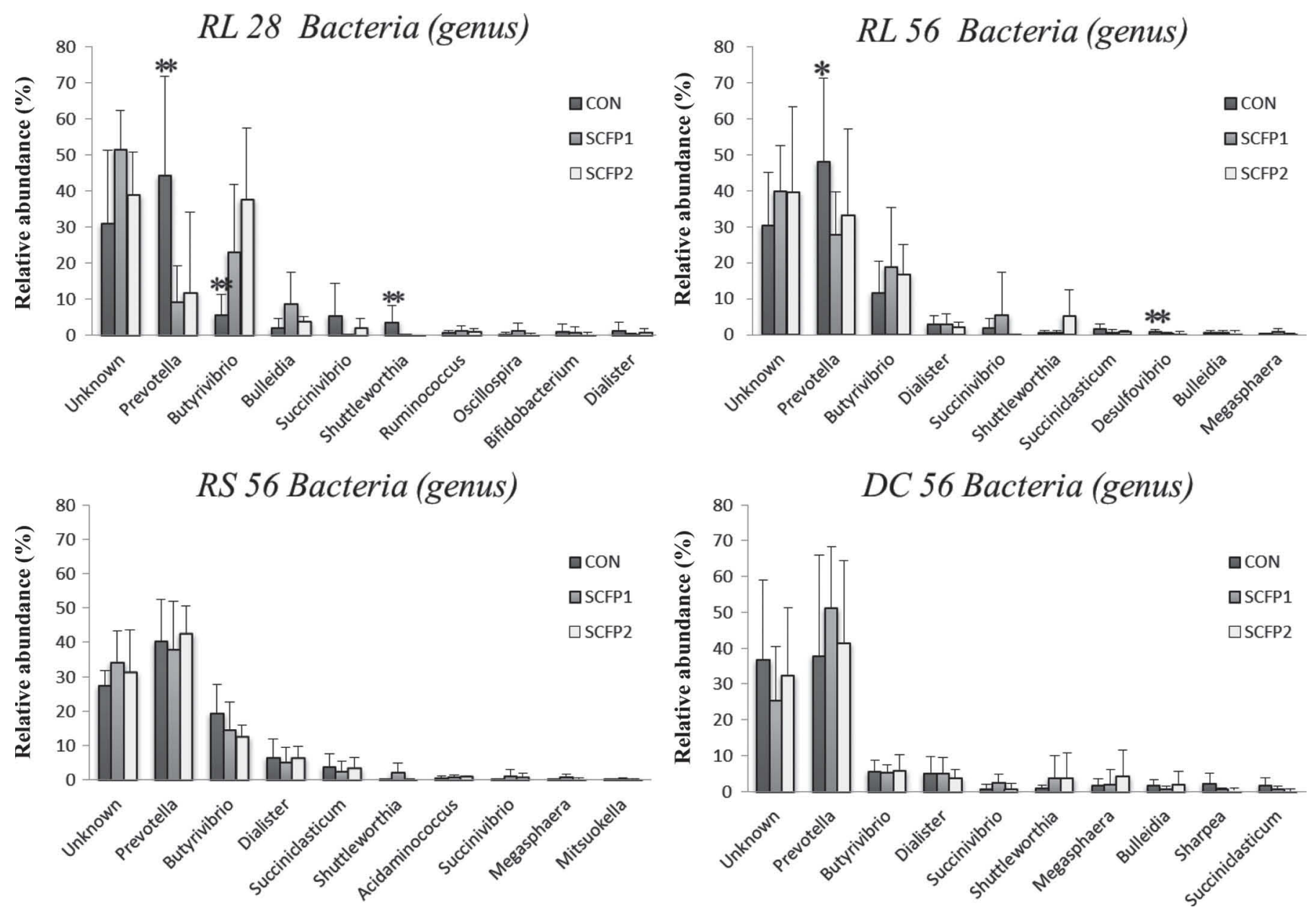

Figure 1. Top 10 bacteria percentage in genus level of total operational taxonomic unit number of control [CON; no SmartCare and XPC (Diamond V, Cedar Rapids, IA), Saccharomyces cerevisiae fermentation products 1 (SCFP1; $1 \mathrm{~g} / \mathrm{head}$ per day of SmartCare in milk $+0.5 \%$ XPC in starter grains), and SCFP2 $(1 \mathrm{~g} /$ head per day of SmartCare in milk $+1 \%$ XPC in the starter grains) in rumen liquid (RL) sampled on d 28 and 56, and rumen solid content (RS) and duodenal content (DC) on d 56. Fifteen calves were used $(\mathrm{CON}=5, \mathrm{SCFP} 1=5, \mathrm{SCFP} 2=5)$. ${ }^{*} P<0.1,{ }^{* *} P<0.05$ between CON and SCFP (SCFP1 and SCFP2). The error bars represent the standard deviation.

development progresses, the contribution of VFA to the energy needs of calves also increases. Most metabolic BHB is converted from butyrate uptake by ruminal papillae (Weigand et al., 1975); as with other ketone bodies, it is a major energy source for the body and an indicator of rumen development.

No treatment and time effects on blood BHB were observed in this and most previous studies (Lesmeister et al., 2004a; Laborde, 2008; Magalhães et al., 2008). In contrast, Coverdale et al. (2004) reported that BHB levels of calves increased with age. Also, Quigley et al. (1992) observed that SCFP increased blood BHB coinciding with an increase in butyrate concentrations. These shifts were only exhibited $4 \mathrm{~h}$ after feeding. In our study, we collected blood samples only once before morning feeding, and the difference in sampling time may explain the lack of treatment effect noted in our study.

\section{Rumen Morphology}

Rumen epithelium plays an important role in shortchain fatty acid absorption (Kramer et al., 1996; Penner et al., 2009), regulation of the protons to prevent severe cytosolic acidosis (Gäbel et al., 2002), and nitrogen transportation and urea recycling (Abdoun et al., 2006; Penner et al., 2009). The normal growth of stratified rumen epithelium that consists of countless papillae as major absorptive structures is critical for nutrient utilization (Graham and Simmons, 2005). Rumen PL and PW have been used to assess the relative development of the rumen (Lesmeister et al., 2004b). 
Most of the findings have shown treatment differences for gastrointestinal morphological measurements when milk feeding (Bühler et al., 1998; Khan et al., 2007) or diet forms were altered (Lesmeister and Heinrichs, 2004). The results from these studies indicated that gastrointestinal morphology was sensitive to physical or chemical changes in the diet.

The effect of SCFP on ruminal morphology has been reported previously. Saccharomyces cerevisiae fermentation products enhanced PL and PW (Lesmeister et al., 2004a; Brewer et al., 2014), and similar positive stimulation of ruminal papillae was obtained in the present study. Besides, papillae surface area was also improved, which means a greater rumen absorption area of VFA and other nutrients substrates. All dorsal and ventral sacs showed statistically or numerically greater PL, PW, and PSA when calves were fed SCFP. As stated above, butyrate serves as a preferred energy source for rumen epithelial cells and plays an important role in the normal development of ruminal papillae. The improvement of papillae might be induced by higher butyrate production by ruminal microbes such as Butyrivibrio.

\section{Intestine Morphology}

Previous studies illustrate that short villi resulted in a reduction of villi surface area and digestive enzymes (Graham et al., 1984). Villus shortening occurs via an increase in rate of cell loss, leading to increased crypt cell production and, finally, increased crypt depth (Pluske et al., 1997). Deeper crypts coinciding with lower VCR value may lead to nutrient malabsorption, which may lead to osmotic diarrhea (Pearson et al., 1978). Thus, SCFP could improve fecal score of calves by improving intestinal absorption of nutrients due to an increased VCR. These proposed benefits were verified in another experiment, which showed an improvement in fecal score and a decrease in diarrhea rate when SCFP was supplemented in the diet (G. Alugongo, J. Xiao, Y. Chung, S. Z. Dong, S. Li, I. Yoon, Z. Wu, and Z. Cao, unpublished data).

Ours is the first study to determine the effect of SCFP on intestinal morphology in calves. We found a significant increase in VH of ESI and a tended decrease in CD of ESI, which resulted in an increase in VCR of the jejunum and ileum and ESI. Furthermore, when calves were supplemented with $1 \%$ of SCFP in the starter, the duodenum and ESI exhibited greater VCR compared with lower dosage of SCFP at $0.5 \%$. Similar results were observed by Shen et al. (2009), who claimed that dietary supplementation of SCFP (Original XP, Diamond V) resulted in greater jejunal $\mathrm{VH}$ and VCR compared with CON in piglets. Gao et al. (2008) also illustrated that broilers fed SCFP (Original XP, Diamond V) reported improved morphological performance. The mechanism of the effect of SCFP on intestinal structural development of broiler, piglets, and calves needs further elucidation.

Saccharomyces cerevisiae fermentation products contain glucans and oligosaccharides, which provide a protective function to the mucosa by preventing pathogens from binding to the villi in the gut (Bode, 2012). Brewer et al. (2014) reported enhanced ruminal papillae development and reduced Salmonella intestinal colonization in SCFP-fed calves when orally challenged with Salmonella; this effect may enhance proliferation of epithelial cells to build the villus (Mourão et al., 2006). More studies should focus on absorptive and metabolic mechanism of action of SCFP in gastrointestinal development and the difference between the supplementation of SCFP in milk and grain.

\section{Bacteria (Genus) Richness}

With the advance of the next-generation sequencing technologies, ours is first study to conduct the $16 \mathrm{~s}$ RNA gene sequencing of microbes to analyze the effect of SCFP on the microbial community and richness in digestive tract of calves. Compared with culturedependent and denaturing gradient gel electrophoresis methods, using next-generation sequencing technology to achieve high coverage can more accurately reflect the community of the gastrointestinal microbiome.

Our sequencing data, spanning the V3 region, was not able to identify all the bacterial groups at species level, but allowed identification of numerous genera (Chakravorty et al., 2007). Over the totality of samples, 244 genera were detected. Among these genera, most sequences belonged to Prevotella followed by Butyrivibrio, which is in accordance with a previous study ( $\mathrm{Li}$ et al., 2012).

The primary motile butyrate-producing anaerobic bacteria in the rumen are mainly of Butyrivibrio fibrisolvens strains, and the major characteristic of bacteria belonging to genus Butyrivibrio is the production of butyric acid (Bryant and Small, 1956; Mrázek et al., 2006). Improvements in cellulolytic bacteria (e.g., Fibrobacter succinogenes and Ruminococcus flavefaciens) when supplemented with SCFP were reported in previous studies (Harrison et al., 1988; Mao et al., 2013); however, studies that reported the effect of SCFP on Butyrivibrio are limited. In vitro studies have shown that SCFP reduce the lag time for growth of Butyrivibrio fibrisolvens D1 (Gumus and Sehu, 2012). In our study, Butyrivibrio richness was increased with SCFP, whereas no significant differences were observed between dosages (SCFP1 vs. SCFP2). Bacteria richness 
was 5.4 fold higher in SCFP than CON at RL28, with no significant effects at RL56 (1.5 fold increase) and RS56 (1.5 fold decrease). The SCFP was supplemented in milk from d 2 to 30 and in starter from d 4 to 56 . This may imply that SCFP had a stronger effect on Butyrivibrio on d 28 when SCFP was supplemented in both milk and starter than d 56 when SCFP was only supplemented via the starter. Additionally, as rumen bacteria are not stable in the first month (Jami et al., 2013), it may be reasonable that SCFP in the starter fast-tracked the establishment of Butyrivibrio by d 28 . Ours is the first study to indicate the effect of SCFP on Butyrivibrio richness in calves. Higher Butyrivibrio genus richness in SCFP potentially contributed to higher butyrate concentration, which resulted in greater ruminal morphology.

Prevotella has been reported to account for a numerically dominant microbial population in the rumen of cattle (Meyer et al., 2008). In agreement with our results, Li et al. (2012) indicated that Prevotella was the most dominant genus at $33.1 \%$ in young calves. Prevotella are highly active hemicellulolytic and proteolytic bacteria that mainly produce acetate and propionate but not butyrate (Matsui et al., 2000). Compared with CON, a lower richness of Prevotella of SCFP treatment at RL28 (4.2 fold decrease) and RL56 (1.6 fold decrease) might also contribute to a higher butyrate concentration.

Furthermore, 2 genus bacteria abundance (Prevotella and Desulfovibrio) were altered in RL56 when calves were supplemented with SCFP compared with CON, but no significant differences were present in RS56. We hypothesized that the changes in richness of genus in RL56, in contrast with those of RS56 (unchanged), may imply that SCFP is more likely to influence liquidassociated rumen bacteria rather than solid-associated ones. The solid fraction is regarded as the main ruminal fraction with highest bacteria population in dairy cows. That most bacteria are attached to solid rather than liquid fractions was demonstrated by Yang et al. (2001), who also indicated that differences in diet composition can influence the proportion of bacteria in 2 fractions. Increasing the forage-to-concentrate ratio is usually beneficial for the pool of bacteria in solid fraction, as more fibrolytic bacteria attach to the forage particles. Faichney (1980) reported that the percentage of solid fraction bacteria reached $90 \%$ in sheep fed only forage, whereas it declined to $50 \%$ for steers fed equal proportions of forage and concentrate (Merry and McAllan, 1983). In the current experiment, we did not feed any forage to calves; as a result, we think the liquid-associated bacteria would represent the general rumen population. However, limited research has been done with calves in this area and further research could help explain why SCFP is more likely to influence liquid-associated rumen bacteria and whether the liquid fraction plays a more important role than the solid fraction in manipulating rumen bacteria or vice versa.

As for genus of Shuttleworthia and Desulfovibrio, limited studies have been reported in calves. Shuttleworthia are saccharolytic bacteria that produce acetate, butyrate, and lactate as end-products of glucose fermentation (Downes et al., 2002). Desulfovibrio are known as the group of sulfate-reducing bacteria (Lobo et al., 2007). No research has been reported on the relationship between SCFP and Desulfovibrio or Shuttleworthia. Although differences were noted between CON and SCFP in these 2 genera, average relative abundances were just 1.3 and $0.7 \%$, respectively, which may lack significance in their regulatory roles.

In general, even though SCFP had positive effects on ruminal microbial establishment and butyrate production, which might connect to the improvement of rumen morphology, some limitations existed in our study. The effects of SCFP on butyrate and Butyrivibrio were significant only on d 28 but not on d 56 , and the effect on rumen bacteria was only in the liquid fraction but not in the solid fraction. Based on these results, we suggest further research with more calves focused on the mechanism of SCFP in regulating the rumen microbial community to explain the changes found in the present study.

\section{CONCLUSIONS}

Saccharomyces cerevisiae fermentation products fed to preweaning calves via milk and starter grains improved ruminal morphology. This was possibly due to manipulating microbial community, which resulted in an increase in ruminal butyrate production, and supplying SCFP, which might provide a protective function to the mucosa by preventing pathogens from binding to the villi in the gut. Furthermore, compared with SCFP1 ( $0.5 \%$ of XPC in starter), SCFP2 (1\% of XPC) tended to exhibit slightly greater effect on gastrointestinal morphology.

\section{ACKNOWLEDGMENTS}

We thank the Dairy Teaching and Research Farm (Shunyi, Beijing, China) for use of their animals and facilities. This work was supported by Diamond V Mills Inc. (No. DVIP 147121, Cedar Rapids, IA) and Tianjing Commission of Science Technology (15YFXQNC00020, Tianjin, China). 


\section{REFERENCES}

Abdoun, K., F. Stumpff, and H. Martens. 2006. Ammonia and urea transport across the rumen epithelium: A review. Anim. Health Res. Rev. 7:43-59.

Anderson, K. L., T. G. Nagaraja, and J. L. Morrill. 1987. Ruminal metabolic development in calves weaned conventionally or early. J. Dairy Sci. 70:1000-1005.

Arakaki, L. C., R. C. Stahringer, J. E. Garrett, and B. A. Dehority. 2000. The effects of feeding monensin and yeast culture, alone or in combination, on the concentration and generic composition of rumen protozoa in steers fed on low-quality pasture supplemented with increasing levels of concentrate. Anim. Feed Sci. Technol. 84:121-127.

Bartram, A. K., M. D. Lynch, J. C. Stearns, G. Moreno-Hagelsieb, and J. D. Neufeld. 2011. Generation of multimillion-sequence $16 \mathrm{~S}$ rRNA gene libraries from complex microbial communities by assembling paired-end Illumina reads. Appl. Environ. Microbiol. $77: 3846-3852$.

Bergman, E. N. 1990. Energy contributions of volatile fatty acids from the gastrointestinal tract in various species. Physiol. Rev. 70:567-590.

Bode, L. 2012. Human milk oligosaccharides: Every baby needs a sugar mama. Glycobiology 22:1147-1162.

Brewer, M. T., K. L. Anderson, I. Yoon, M. Scott, and S. A. Carlson. 2014. Amelioration of salmonellosis in pre-weaned dairy calves fed Saccharomyces cerevisiae fermentation products in feed and milk replacer. Vet. Microbiol. 172:248-255.

Broderick, G. A., and J. H. Kang. 1980. Automated simultaneous determination of ammonia and total amino acids in ruminal fluid and in vitro media. J. Dairy Sci. 63:64-75.

Bryant, M. P., and N. Small. 1956. The anaerobic monotrichous butyric acid-producing curved rod-shaped bacteria of the rumen. J. Bacteriol. 72:16-21.

Bühler, C., H. Hammon, G. L. Rossi, and J. W. Blum. 1998. Small intestinal morphology in eight-day-old calves fed colostrum for different durations or only milk replacer and treated with long-R3insulin-like growth factor I and growth hormone. J. Anim. Sci. 76:758-765.

Callaway, E. S., and S. A. Martin. 1997. Effects of a Saccharomyces cerevisiae culture on ruminal bacteria that utilize lactate and digest cellulose. J. Dairy Sci. 80:2035-2044.

Chakravorty, S., D. Helb, M. Burday, N. Connell, and D. Alland. 2007. A detailed analysis of $16 \mathrm{~S}$ ribosomal RNA gene segments for the diagnosis of pathogenic bacteria. J. Microbiol. Methods 69:330-339.

Coverdale, J. A., H. D. Tyler, J. D. Quigley, and J. A. Brumm. 2004 Effect of various levels of forage and form of diet on rumen development and growth in calves. J. Dairy Sci. 87:2554-2562.

Dann, H. M., J. K. Drackley, G. C. McCoy, M. F. Hutjens, and J. E. Garrett. 2000. Effects of yeast culture (Saccharomyces cerevisiae) on prepartum intake and postpartum intake and milk production of Jersey cows. J. Dairy Sci. 83:123-127.

Downes, J., M. A. Munson, D. R. Radford, D. A. Spratt, and W. G. Wade. 2002. Shuttleworthia satelles gen. nov., sp. nov., isolated from the human oral cavity. Int. J. Syst. Evol. Microbiol. 52:14691475 .

Edgar, R. C. 2010. Search and clustering orders of magnitude faster than BLAST. Bioinformatics 26:2460-2461.

Erwin, E. S., G. J. Marco, and E. M. Emery. 1961. Volatile fatty acid analyses of blood and rumen fluid by gas chromatography. J. Dairy Sci. 9:1768-1771.

Faichney, G. 1980. Measurement in sheep of the quantity and composition of rumen digesta and of the fractional outflow rates of digesta constituents. Crop Pasture Sci. 31:1129-1137.

Fliegerova, K., I. Tapio, A. Bonin, J. Mrazek, M. L. Callegari, P. Bani, A. Bayat, J. Vilkki, J. Kopecny, K. J. Shingfield, F. Boyer, E. Coissac, P. Taberlet, and R. J. Wallace. 2014. Effect of DNA extraction and sample preservation method on rumen bacterial population. Anaerobe 29:80-84.
Gäbel, G., J. R. Aschenbach, and F. Muller. 2002. Transfer of energy substrates across the ruminal epithelium: Implications and limitations. Anim. Health Res. Rev. 3:15-30.

Gäbel, G., and J. Sehested. 1997. SCFA transport in the forestomach of ruminants. Comp. Biochem. Physiol. A. Physiol. 118:367-374.

Gao, J., H. J. Zhang, S. H. Yu, S. G. Wu, I. Yoon, J. Quigley, Y. P. Gao, and G. H. Qi. 2008. Effects of yeast culture in broiler diets on performance and immunomodulatory functions. Poult. Sci 87:1377-1384.

Graham, C., and N. L. Simmons. 2005. Functional organization of the bovine rumen epithelium. Am. J. Physiol. Regul. Integr. Comp. Physiol. 288:R173-R181.

Graham, D. Y., J. W. Sackman, and M. K. Estes. 1984. Pathogenesis of rotavirus-induced diarrhea. Dig. Dis. Sci. 29:1028-1035.

Gumus, H., and A. Sehu. 2012. The usage of yeast and yeast product in ruminant. Anim. Stud. Vet. Med. 2:5.

Harrison, G. A., R. W. Hemken, K. A. Dawson, R. J. Harmon, and K. B. Barker. 1988. Influence of addition of yeast culture supplement to diets of lactating cows on ruminal fermentation and microbial populations. J. Dairy Sci. 71:2967-2975.

Heinrichs, A. J., and K. E. Lesmeister. 2005. Rumen development in the dairy calf. Pages 179-187 in Calf and Heifer Rearing: Principles of Rearing the Modern Dairy Heifer from Calf to Calving. 60th University of Nottingham Easter School in Agricultural Science, Nottingham, UK. Nottingham University Press, Nottingham, UK.

Hristov, A. N., G. Varga, T. Cassidy, M. Long, K. Heyler, S. K. Karnati, B. Corl, C. J. Hovde, and I. Yoon. 2010. Effect of Saccharomyces cerevisiae fermentation product on ruminal fermentation and nutrient utilization in dairy cows. J. Dairy Sci. 93:682-692.

Jami, E., A. Israel, A. Kotser, and I. Mizrahi. 2013. Exploring the bovine rumen bacterial community from birth to adulthood. ISME. J. 7:1069-1079.

Khan, M. A., H. J. Lee, W. S. Lee, H. S. Kim, K. S. Ki, T. Y. Hur, G. H. Suh, S. J. Kang, and Y. J. Choi. 2007. Structural growth, rumen development, and metabolic and immune responses of Holstein male calves fed milk through step-down and conventional methods. J. Dairy Sci. 90:3376-3387.

Kramer, T., T. Michelberger, H. Gurtler, and G. Gabel. 1996. Absorption of short-chain fatty acids across ruminal epithelium of sheep. J. Comp. Physiol. B 166:262-269.

Kumar, U., V. K. Sareen, and S. Singh. 1994. Effect of Saccharomyces cerevisiae yeast culture supplement on ruminal metabolism in buffalo calves given a high concentrate diet. Anim. Prod. 59:209-215.

Laborde, J. M. 2008. Effects of probiotics and yeast culture on rumen development and growth of dairy calves. MS thesis, Louisiana State University, Baton Rouge.

Lesmeister, K. E., and A. J. Heinrichs. 2004. Effects of corn processing on growth characteristics, rumen development, and rumen parameters in neonatal dairy calves. J. Dairy Sci. 87:3439-3450.

Lesmeister, K. E., A. J. Heinrichs, and M. T. Gabler. 2004a. Effects of supplemental yeast (Saccharomyces cerevisiae) culture on rumen development, growth characteristics, and blood parameters in neonatal dairy calves. J. Dairy Sci. 87:1832-1839.

Lesmeister, K. E., P. R. Tozer, and A. J. Heinrichs. 2004b. Development and analysis of a rumen tissue sampling procedure. J. Dairy Sci. 87:1336-1344.

Li, R. W., E. E. Connor, C. Li, V. I. Baldwin, L. Ransom, and M. E. Sparks. 2012. Characterization of the rumen microbiota of preruminant calves using metagenomic tools. Environ. Microbiol. 14:129-139.

Lobo, S. A., A. M. Melo, J. N. Carita, M. Teixeira, and L. M. Saraiva. 2007. The anaerobe Desulfovibrio desulfuricans ATCC 27774 grows at nearly atmospheric oxygen levels. FEBS Lett. 581:433-436.

Magalhães, V. J., F. Susca, F. S. Lima, A. F. Branco, I. Yoon, and J. E. Santos. 2008. Effect of feeding yeast culture on performance, health, and immunocompetence of dairy calves. J. Dairy Sci. 91:1497-1509.

Malmuthuge, N., and P. J. Griebel. 2014. Taxonomic identification of commensal bacteria associated with the mucosa and digesta throughout the gastrointestinal tracts of preweaned calves. Appl Environ. Microbiol. 80:2021-2028. 
Mao, H. L., H. Mao, J. K. Wang, J. X. Liu, and I. Yoon. 2013. Effects of Saccharomyces cerevisiae fermentation product on in vitro fermentation and microbial communities of low-quality forages and mixed diets. J. Anim. Sci. 91:3291-3298.

Matsui, H., K. Ogata, K. Tajima, M. Nakamura, T. Nagamine, R. I. Aminov, and Y. Benno. 2000. Phenotypic characterization of polysaccharidases produced by four Prevotella type strains. Curr. Microbiol. 41:45-49.

McCarthy, R. D., and E. M. Kesler. 1956. Relation between age of calf, blood glucose, blood and rumen levels of volatile fatty acids, and in vitro cellulose digestion. J. Dairy Sci. 9:1280-1287.

Merry, R. J., and A. McAllan. 1983. A comparison of the chemical composition of mixed bacteria harvested from the liquid and solid fractions of rumen digesta. Br. J. Nutr. 50:701-709.

Meyer, M., U. Stenzel, and M. Hofreiter. 2008. Parallel tagged sequencing on the 454 platform. Nat. Protoc. 3:267-278.

Morales, E., A. Pérez, A. I. García, D. R. Nez-Ruiz, P. Frutos, and G. Hervás. 2014. Use of stomach tubing as an alternative to rumen cannulation to study ruminal fermentation and microbiota in sheep and goats. Anim. Feed Sci. Technol. 198:57-66.

Mourão, J. L., V. Pinheiro, A. Alves, C. M. Guedes, L. Pinto, M. J. Saavedra, P. Spring, and A. Kocher. 2006. Effect of mannan oligosaccharides on the performance, intestinal morphology and cecal fermentation of fattening rabbits. Anim. Feed Sci. Technol. 126:107-120.

Mrázek, J., K. Tepšič, G. Avguštin, and J. Kopečný. 2006. Diet-dependent shifts in ruminal butyrate-producing bacteria. Folia Microbiol. (Praha) 51:294-298.

NRC. 2001. Nutrient Requirements of Dairy Cattle. 7th rev. ed. Natl. Acad. Sci. Washington, DC.

Pearson, G. R., M. S. McNulty, and E. F. Logan. 1978. Pathological changes in the small intestine of neonatal calves naturally infected with reo-like virus (rotavirus). Vet. Rec. 102:454-458.

Penner, G. B., J. R. Aschenbach, G. Gabel, R. Rackwitz, and M. Oba. 2009. Epithelial capacity for apical uptake of short chain fatty acids is a key determinant for intraruminal $\mathrm{pH}$ and the susceptibility to subacute ruminal acidosis in sheep. J. Nutr. 139:1714-1720.

Pluske, J. R., D. J. Hampson, and I. H. Williams. 1997. Factors influencing the structure and function of the small intestine in the weaned pig: A review. Livest. Prod. Sci. 51:215-236.

Poppy, G. D., A. R. Rabiee, I. J. Lean, W. K. Sanchez, K. L. Dorton, and P. S. Morley. 2012. A meta-analysis of the effects of feeding yeast culture produced by anaerobic fermentation of Saccharomyces cerevisiae on milk production of lactating dairy cows. J. Dairy Sci. 95:6027-6041.

Prates, A., J. A. De Oliveira, L. Abecia, and M. Fondevila. 2010. Effects of preservation procedures of rumen inoculum on in vitro microbial diversity and fermentation. Anim. Feed Sci. Technol. 155:186-193.

Quigley, J. D., III, Z. P. Smith, and R. N. Heitmann. 1991. Changes in plasma volatile fatty acids in response to weaning and feed intake in young calves. J. Dairy Sci. 74:258-263.

Quigley, J. D., III, L. B. Wallis, H. H. Dowlen, and R. N. Heitmann. 1992. Sodium bicarbonate and yeast culture effects on ruminal fermentation, growth, and intake in dairy calves. J. Dairy Sci $75: 3531-3538$.

Roffler, B., A. Fah, S. N. Sauter, H. M. Hammon, P. Gallmann, G. Brem, and J. W. Blum. 2003. Intestinal morphology, epithelial cell proliferation, and absorptive capacity in neonatal calves fed milkborn insulin-like growth factor-I or a colostrum extract. J. Dairy Sci. 86:1797-1806.

Sakata, T., and H. Tamate. 1978. Rumen epithelial cell proliferation accelerated by rapid increase in intraruminal butyrate. J. Dairy Sci. 61:1109-1113.

Saner, E. G., R. G. Warner, H. N. Harrison, and J. K. Loosli. 1959. The stimulatory effect of sodium butyrate and sodium propionate on the development of rumen mucosa in the young calf. J. Dairy Sci. 42:1600-1605.

Schloss, P. D., and J. Handelsman. 2005. Introducing DOTUR, a computer program for defining operational taxonomic units and estimating species richness. Appl. Environ. Microbiol. 71:1501-1506.

Shen, Y. B., X. S. Piao, S. W. Kim, L. Wang, P. Liu, I. Yoon, and Y. G. Zhen. 2009. Effects of yeast culture supplementation on growth performance, intestinal health, and immune response of nursery pigs. J. Anim. Sci. 87:2614-2624.

Suchodolski, J. S., J. Camacho, and J. M. Steiner. 2008. Analysis of bacterial diversity in the canine duodenum, jejunum, ileum, and colon by comparative $16 \mathrm{~S}$ rRNA gene analysis. FEMS Microbiol. Ecol. 66:567-578.

Tamate, H., A. D. McGilliard, N. L. Jacobson, and R. Getty. 1962. Effect of various dietaries on the anatomical development of the stomach in the calf. J. Dairy Sci. 45:408-420.

Trotz-Williams, L. A., K. Leslie, and A. Peregrine. 2008. Passive immunity in Ontario dairy calves and investigation of its association with calf management practices. J. Dairy Sci. 91:3840-3849.

Vlková, E., I. Trojanova, and V. Rada. 2006. Distribution of bifidobacteria in the gastrointestinal tract of calves. Folia Microbiol (Praha) 51:325-328.

Weigand, E., J. W. Young, and A. D. McGilliard. 1975. Volatile fatty acid metabolism by rumen mucosa from cattle fed hay or grain. J. Dairy Sci. 58:1294-1300.

Williamson, D. H., J. Mellanby, and H. A. Krebs. 1962. Enzymic determination of $\mathrm{D}(-)-\beta$-hydroxybutyric acid and acetoacetic acid in blood. Biochem. J. 82:90.

Yang, W. Z., K. Beauchemin, and L. Rode. 2001. Effect of dietary factors on distribution and chemical composition of liquid-or solidassociated bacterial populations in the rumen of dairy cows. J. Anim. Sci. 79:2736-2746.

Yoon, I. K., and M. D. Stern. 1996. Effects of Saccharomyces cerevisiae and Aspergillus oryzae cultures on ruminal fermentation in dairy cows. J. Dairy Sci. 79:411-417.

Zitnan, R., S. Kuhla, K. Nurnberg, U. Schonhusen, Z. Ceresnakova, A. Sommer, M. Baran, G. Greserova, and J. Voigt. 2003. Influence of the diet on the morphology of ruminal and intestinal mucosa and on intestinal carbohydrase levels in cattle. Vet. Med. Czech 48:177-182. 